\title{
Estimation of global solar radiation using clear sky radiation in Yemen
}

\author{
M. Maroof Khan* and M. Jamil Ahmad
}

${ }^{1}$ Department of Mechanical Engineering, Aligarh Muslim University, Aligarh 202002, India

Received 28 December 2011; Accepted 20 August 2012

\begin{abstract}
In this communication, the usability of clear sky radiation for predicting the average global solar radiation has been investigated. For this aim, the various regression analyses were applied by using $S / S_{o}$ and $S / S_{n h}$ parameters. Also, equations which represent the two periods of the year, winter and summer, were developed by using these parameters. The equations developed by using $S / S_{o}$ and $S / S_{n h}$ have approximately the same results. Having the better values of the equations developed by using the change of summer and winter is another result. In addition, the use of the RMSE and MBE in isolation is not an adequate indicator of model performance. Using the $t$-statistic method and the harmony of results obtained with each method prove that the results are reliable.
\end{abstract}

Keywords: Clear sky radiation, Estimation of solar radiation, $t$-statistic.

\section{Introduction}

The solar radiation, through atmosphere, reaching the earth's surface can be classified into two components: beam radiation and diffuse radiation. Beam radiation is the solar radiation propagating along the line joining the receiving surface and the sun. It is also referred to as direct radiation. Diffuse radiation is the solar radiation scattered by aerosols, dust and molecules, it does not have a unique direction. The total radiation is the sum of the beam and diffuses radiation and is sometimes referred to as the global radiation. When the amount of diffuse radiation reaching the earth's surface is less than or equal to $25 \%$ of global radiation, the sky is termed as clear sky.

In many applications of solar energy, the solar irradiance incident on the surface of the earth at the location of interest is an important input parameter. The temporal and spatial fluctuations of such irradiance necessitate a method to predict them. The systematic variation of solar irradiance outside the earth's atmosphere makes it possible to introduce many models for such prediction [1].

Knowledge of global solar irradiance at a site is essential for the proper design and assessment of flat plate types solar energy conversion systems. Some of the systems such as concentrating systems require information on direct beam component whereas in the case of tilted plain surfaces the diffuse component of solar irradiance is also important for the computation of system performance [2]. However, at locations on the Earth's surface, the solar radiation is also a function of such variables as the nature and extent of cloud cover, the aerosol and water vapour content of atmosphere, etc. Good prediction of the actual value of solar irradiance for a given location requires, in principle, long-term, average meteorological data, which are still scarce for developing countries [3-5]. It is, therefore, not always possible to predict the actual value of solar irradiance for a given location.

There are several formulae that relate global radiation to other climatological parameters such as sunshine hours, relative humidity, max. temperature, and average temperature. The first correlation proposed for estimating the monthly average daily global irradiation is due to Angstrom [6]. The original Angstrom-type regression equation related monthly average daily radiation to clear day radiation at the location in the question and average fraction of possible sunshine hours:

$$
H / H_{c}=a+b\left(S / S_{o}\right)
$$

A basic difficulty with Eq. (1) lies in the ambiguity of the terms $S / S_{o}$ and $H_{c}$. Page [7] and the other have modified the method to base it on extraterrestrial radiation on a horizontal surface rather than on clear sky day radiation.

$H / H_{o}=a^{\prime}+b^{\prime}\left(S / S_{o}\right)$

Where $H_{\mathrm{o}}$ is the extraterrestrial radiation $\left(\mathrm{MJ} / \mathrm{m}^{2}\right)$ and $a^{\prime}$ and $b^{\prime}$ are constant depending on location. In spite of having complication of $H_{c}$ calculations, the better results were obtained by using $H_{c}$ instead of $H_{o}$ [8].

The major objective of this article is to investigate usability of clear sky radiation to predict and express the average measured values of solar irradiance on a horizontal surface by using various regression analyses in Yemen.

\footnotetext{
*E-mail address: maroof141@yahoo.com

ISSN: 1791-2377 @ 2012Kavala Institute of Technology. All rights reserved.
} 


\subsection{Estimation of clear sky radiation}

Hottel [9] has presented a method for estimating the beam radiation transmitted through clear atmospheres which takes into account zenith angle and altitude for a standard atmosphere and four climate types. The atmospheric transmittance for beam radiation $\tau_{\mathrm{b}}$ is given in the form:

$\tau_{\mathrm{b}}=a_{o}+a_{l} \exp \left(-k / \cos \theta_{\mathrm{z}}\right)$

The constant $a_{o}, a_{l}$ and $k$ for the standard atmosphere with $23 \mathrm{~km}$ visibility are found from $\mathrm{a}_{0} *, \mathrm{a}_{1} *$ and $k^{*}$ which are given for altitudes less than $2.5 \mathrm{~km}$ by

$\mathrm{a}_{\mathrm{o}} * 0.4237-0.00821(6-\mathrm{A})^{2}$

$\mathrm{a}_{1} *=0.5055+0.00595(6.5-\mathrm{A})^{2}$

$k^{*}=0.2711+0.01858(2.5-\mathrm{A})^{2}$

where $\mathrm{A}$ is the altitude of the observer in kilometers.

The correction factors are applied to $\mathrm{a}_{\mathrm{o}}{ }^{*}, \mathrm{a}_{1}{ }^{*}$ and $k^{*}$ to allow for changes in climate types.

The correction factors $\mathrm{r}_{\mathrm{o}}=\mathrm{a}_{\mathrm{o}} / \mathrm{a}_{\mathrm{o}} *, \mathrm{r}_{1}=\mathrm{a}_{1} / \mathrm{a}_{1} *$ and $\mathrm{r}_{\mathrm{k}}=k /$ $k^{*}$ are given in Table 1 .

Thus, the transmittance of this standard atmosphere for beam radiation can be determined for any zenith angle and any altitude up to $2.5 \mathrm{~km}$. The clear sky beam radiation $\left(\mathrm{G}_{\mathrm{cb}}\right.$, $\mathrm{Wm}^{-2}$ ) is than

$\mathrm{G}_{\mathrm{cb}}=\mathrm{G}_{\mathrm{on}} \tau_{\mathrm{b}}$

Where $G_{\text {on }}$ is the extraterrestrial radiation, measured on the plane normal to the radiation on the $n$th day of the year and given in the following form $\left(\mathrm{W} \mathrm{m}^{-2}\right)$.

$\mathrm{G}_{\mathrm{on}}=\mathrm{G}_{\mathrm{sc}}(1+0.033 \cos (360 \mathrm{n} / 365))$

Where $\mathrm{G}_{\mathrm{sc}}$ is the solar constant and is equal to $1367 \mathrm{~W} \mathrm{~m}^{-2}$.

The clear sky horizontal beam radiation is

$\mathrm{G}_{\mathrm{cb}}=\mathrm{G}_{\mathrm{on}} \tau_{\mathrm{b}} \cos \theta_{\mathrm{z}}$

It is also necessary to estimate the clear sky diffuse radiation on a horizontal surface to get the total radiation Liu and Jordan [10] developed in an empirical relationship between the transmission coefficient for beam and diffuse radiation for clear days.

$\tau_{\mathrm{d}}=0.271-0.294 \tau_{\mathrm{b}}$

Table 1. Correction factors for climate types.

\begin{tabular}{llll}
\hline Climate type & $\mathbf{r}_{\mathbf{0}}$ & $\mathbf{r}_{1}$ & $\mathbf{r}_{\mathbf{k}}$ \\
\hline Tropical & 0.95 & 0.98 & 1.02 \\
Midlatitude summer & 0.97 & 0.99 & 1.02 \\
Subarctic summer & 0.99 & 0.99 & 1.01 \\
Midlatitude winter & 1.03 & 1.01 & 1.00 \\
\hline
\end{tabular}

where $\tau_{\mathrm{d}}$ is the ratio of diffuse radiation to the extraterrestrial (beam) radiation on the horizontal plane. The clear sky diffuse radiation $\mathrm{G}_{\mathrm{cd}}\left(\mathrm{Wm}^{-2}\right)$

$\mathrm{G}_{\mathrm{cd}}=\mathrm{G}_{\mathrm{on}} \tau_{\mathrm{d}} \cos \theta_{\mathrm{z}}$

The clear sky global solar radiation is given by

$\mathrm{G}_{\mathrm{c}}=\mathrm{G}_{\mathrm{cb}}+\mathrm{G}_{\mathrm{cd}}$

\section{Data}

The objective of this study is to develop some statistical relations to estimate monthly mean daily global solar radiation by using clear sky radiation in Yemen. For this aim, the department of Physics of Sana'a University, the Meteorological Department of the Civil Aviation and Meteorological Authority in Sana'a installed on the roof of the Faculty of Science building a few Eppley pyranometers and a pyrheliometer comprising electronic integrators and printers for recording global, diffuse and beam solar irradiances. An actinograph and a Campbell- Stokes sunshine recorder were also installed at the same site. These instruments are often checked and calibrated to maintain an accuracy of at least 5 per cent. The maximum difference between the actinograph records and the Eppley pyranometer which registers global irradiance does not exceed 5 per cent.

Another meteorological station in Sana'a is the airport station which has been recording duration of sunshine and global solar irradiance by means of an actinography. There are meteorological stations in five other towns of Yemen [2].

The longitude, latitude and altitude of the six cities are given in Table 2. The measured values of the monthly average global solar radiation $G$ and the monthly average daily hours of bright sunshine $S$ for six locations are given in Table $3 . G_{c}$ values calculated for six cities are given in Table 4. The correlations have been studied by using both the ratios $S / S_{o}$ and $S / S_{n h}$, where $S_{n h}$ is the monthly mean sunshine duration taking into account the natural horizon of the site, and is given in the following equation

$\frac{1}{S_{n h}}=\frac{0.8706}{S_{o}}+0.0003$

In this work, we developed equations to estimate monthly mean global solar radiation $\mathrm{G}$, applying various regression types to parameter such as $S / S_{o}$ and $S / S_{n h}$. The effects which the solar radiation is exposed to until it reaches to the earth from the atmosphere change a lot for winter and summer. Therefore it will be a true approach to compute the reaching monthly mean global solar radiation for both summer (April - September) and winter (October - March). Thus the relation between $\mathrm{G} / \mathrm{G}_{\mathrm{c}}=f\left(S / S_{o}\right)$ and $\mathrm{G} / \mathrm{G}_{\mathrm{c}}=f\left(S / S_{n h}\right)$ were investigated by different regression analyses for the whole year as well as for the two period of the year i.e. summer \& winter.

The values of $G$ were estimated by using these developed equations. These values were then compared with original measured values for each city. 
Table 2. Geographical location of six Yemen cities.

\begin{tabular}{lccc}
\hline \multicolumn{1}{c}{ Station (State) } & Longitude $\left({ }^{\mathbf{O}} \mathbf{E}\right)$ & Latitude $\left({ }^{\circ} \mathbf{N}\right)$ & Altitude (m) \\
\hline Sana'a & 44.26 & 15.52 & 2210 \\
El Boun & 44.97 & 15.73 & 2100 \\
Hodeidah & 42.98 & 14.75 & 33 \\
El kahber & 44.83 & 14.38 & 2100 \\
Taiz & 43.95 & 13.58 & 1400 \\
El Macha & 43.28 & 13.25 & 10 \\
\hline
\end{tabular}

Table 3. Measured values of monthly average global solar radiation $(\mathrm{G})$ and $\mathrm{S} /$ So for six cities.[2]

\begin{tabular}{lcccccccccccccc}
\hline & \multicolumn{2}{c}{ Sana'a } & \multicolumn{2}{c}{ El Boun } & \multicolumn{2}{c}{ Hodeidah } & \multicolumn{2}{c}{ El Khaber } & \multicolumn{2}{c}{ Taiz } \\
\hline Month & G & S/So & G & S/So & G & S/So & G & S/So & G & S/So & G & S/So \\
\hline Jan & 5.31 & 0.842 & NA & 0.7248 & 4.97 & 0.748 & 4.86 & 0.7555 & 5.08 & 0.6818 & 5 & 0.7161 \\
Feb & 5.78 & 0.8557 & 6.22 & 0.9214 & 4.91 & 0.7281 & 6 & 0.8745 & 5.72 & 0.7516 & 5.55 & 0.7509 & 0.753 \\
Mar & 5.67 & 0.7347 & 6.03 & 0.7893 & 5.97 & 0.6966 & 6.05 & 0.7468 & 5.92 & 0.7633 & 6.39 & 0.7128 \\
Apr & 6.19 & 0.7222 & 6.58 & 0.7607 & 6.38 & 0.7378 & 6.78 & 0.8357 & 5.81 & 0.7557 & 6.94 & 0.7806 \\
May & 6.08 & 0.7231 & 6.25 & 0.7461 & 6.17 & 0.7568 & 6.64 & 0.7894 & 5.89 & 0.7127 & NA & 0.7611 \\
Jun & 6.5 & 0.7028 & 6.42 & 0.7199 & 5.83 & 0.6532 & 6.25 & 0.7245 & NA & 0.6099 & 6.22 & 0.5952 \\
Jul & 5.67 & 0.5755 & NA & 0.6233 & 5.58 & 0.5477 & 5.44 & 0.5799 & NA & 0.5033 & 6.08 & 0.5749 \\
Aug & 5.64 & 0.5996 & 6.19 & 0.6392 & 5.3 & 0.5769 & 5.22 & 0.5373 & NA & 0.5867 & 5.89 & 0.5631 \\
Sep & 6.34 & 0.7449 & 5.89 & 0.7779 & 5.47 & 0.621 & 5.92 & 0.7287 & NA & 0.6213 & 5.83 & 0.6214 \\
Oct & 6.25 & 0.859 & 6.89 & 0.8766 & 5.78 & 0.7204 & 6.17 & 0.8913 & 5.38 & 0.7957 & 6.22 & 0.8123 \\
Nov & 5.45 & 0.865 & 6.17 & 0.888 & 5.17 & 0.8046 & 5.75 & 0.9092 & 5.11 & 0.8006 & 5.75 & 0.8697 \\
Dec & 5.19 & 0.858 & 5.47 & 0.8843 & 4.83 & 0.7718 & 5.5 & 0.9315 & 4.72 & 0.7848 & 5.22 & 0.819 \\
\hline
\end{tabular}

Table 4. Gc values for each city (using Hottle model) in $\mathrm{KW} / \mathrm{m}^{2} /$ day.

\begin{tabular}{lcccccc}
\hline Months & Sana'a & El Boun & Hodeidah & El Khaber & Taiz & EI Macha \\
\hline Jan & 5.9753 & 5.9292 & 6.0374 & 6.0777 & 5.9604 & 5.2863 \\
Feb & 6.6978 & 6.6557 & 6.7395 & 6.7705 & 6.6237 & 5.9055 \\
Mar & 7.3992 & 7.3638 & 7.4121 & 7.4298 & 7.2465 & 6.4882 \\
Apr & 7.8189 & 7.7919 & 7.7991 & 7.8011 & 7.5814 & 6.7987 \\
May & 7.8638 & 7.8438 & 7.8188 & 7.8086 & 7.5644 & 6.7767 \\
Jun & 7.7908 & 7.7741 & 7.7348 & 7.7193 & 7.4657 & 6.6808 \\
Jul & 7.7924 & 7.7743 & 7.7414 & 7.7284 & 7.4800 & 6.6972 \\
Aug & 7.7943 & 7.7705 & 7.7637 & 7.7605 & 7.5319 & 6.7531 \\
Sep & 7.5235 & 7.4917 & 7.5236 & 7.5350 & 7.3391 & 6.5777 \\
Oct & 6.8813 & 6.8416 & 6.9136 & 6.9402 & 6.7831 & 6.0577 \\
Nov & 6.1314 & 6.0865 & 6.1881 & 6.2260 & 6.1019 & 5.4200 \\
Dec & 5.7404 & 5.6935 & 5.8074 & 5.8500 & 5.7411 & 5.0829 \\
\hline
\end{tabular}

\section{Equations}

The following equations were obtained when we investigated the relation between $S / S_{o}$ and $\mathrm{G} / \mathrm{G}_{\mathrm{c}}$ by trying different regression types. The scatter of monthly mean values between $S / S_{o}$ and $\mathrm{G} / \mathrm{G}_{\mathrm{c}}$ are given in Fig. 1

$\mathrm{G} / \mathrm{G}_{\mathrm{c}}=0.5152\left(S / S_{o}\right)+0.4603$

$$
\mathrm{G} / \mathrm{G}_{\mathrm{c}}=0.9078\left(S / S_{o}\right)^{2}-0.8153\left(S / S_{o}\right)+0.9387
$$

$$
\begin{aligned}
& \mathrm{G} / \mathrm{G}_{\mathrm{c}}=4.0401\left(S / S_{o}\right)^{3}-8.01\left(S / S_{o}\right)^{2}+5.6524\left(S / S_{o}\right)-0.6001 \\
& \mathrm{G} / \mathrm{G}_{\mathrm{c}}=0.9607\left(S / S_{o}\right)^{0.4417} \\
& \mathrm{G} / \mathrm{G}_{\mathrm{c}}=0.3639 \ln \left(S / S_{o}\right)+0.9547
\end{aligned}
$$


$\mathrm{G} / \mathrm{G}_{\mathrm{c}}=0.5281 \mathrm{e}^{0.623\left(S / S_{o}\right)}$

The results of regression analyses applied for summer (April- September) are given below.

$\mathrm{G} / \mathrm{Gc}=0.336(\mathrm{~S} / \mathrm{So})+0.5737$

$\mathrm{G} / \mathrm{G}_{\mathrm{c}}=0.6173\left(S / S_{o}\right)^{2}-0.4944\left(S / S_{o}\right)+0.8485$

$\mathrm{G} / \mathrm{G}_{\mathrm{c}}=27.308\left(S / S_{o}\right)^{3}-55.698\left(S / S_{o}\right)^{2}+37.874\left(S / S_{o}\right)-7.7809(22 \mathrm{a})$

$\mathrm{G} / \mathrm{G}_{\mathrm{c}}=0.8969\left(S / S_{o}\right)^{0.2938}$

$\mathrm{G} / \mathrm{G}_{\mathrm{c}}=0.2226 \ln \left(S / S_{o}\right)+0.8898$

$\mathrm{G} / \mathrm{G}_{\mathrm{c}}=0.5915 \mathrm{e}^{0.442\left(S / S_{o}\right)}$

The results of regression analyses applied for winter (October - March) are given below.

$\mathrm{G} / \mathrm{G}_{\mathrm{c}}=0.5524\left(S / S_{o}\right)+0.4377$

$\mathrm{G} / \mathrm{G}_{\mathrm{c}}=2.3437\left(S / S_{o}\right)^{2}-3.2345\left(S / S_{o}\right)+1.9561$

$\mathrm{G} / \mathrm{G}_{\mathrm{c}}=-50.088\left(S / S_{o}\right)^{3}+123.58\left(S / S_{o}\right)^{2}-100.62\left(S / S_{o}\right)+27.914(22 \mathrm{~b})$

$\mathrm{G} / \mathrm{G}_{\mathrm{c}}=0.9829\left(S / S_{o}\right)^{0.505}$

$\mathrm{G} / \mathrm{G}_{\mathrm{c}}=0.4387 \ln \left(S / S_{o}\right)+0.9792$

$\mathrm{G} / \mathrm{G}_{\mathrm{c}}=0.527 \mathrm{e}^{0.6359\left(S / S_{o}\right)}$

The linear regression analyses to investigate the usability of $S / S_{n h}$ ratio for computing the monthly mean global solar radiation were made. The results of these analyses can be seen as the following equations. The effect of $S / S_{n h}$ on the $\mathrm{G} / \mathrm{G}_{\mathrm{c}}$ is given in Fig. 2

$\mathrm{G} / \mathrm{G}_{\mathrm{c}}=0.5899\left(S / S_{n h}\right)+0.46$

$\mathrm{G} / \mathrm{G}_{\mathrm{c}}=1.189\left(S / S_{n h}\right)^{2}-0.9343\left(S / S_{n h}\right)+0.9391$

$\mathrm{G} / \mathrm{G}_{\mathrm{c}}=6.0901\left(\mathrm{~S} / \mathrm{S}_{n h}\right)^{3}-10.562\left(\mathrm{~S} / \mathrm{S}_{n h}\right)^{2}+6.5159\left(\mathrm{~S} / \mathrm{S}_{n h}\right)-0.6106(28)$

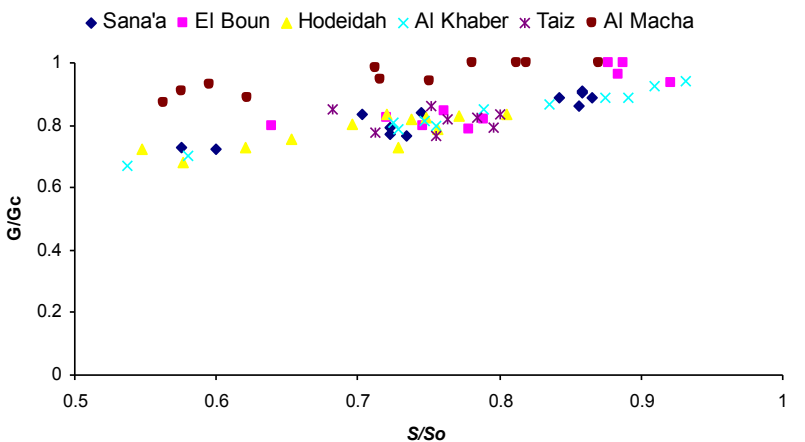

Fig. 1. The variation of $G / G_{c} V s ~ S / S o$ for six towns in Yemen.

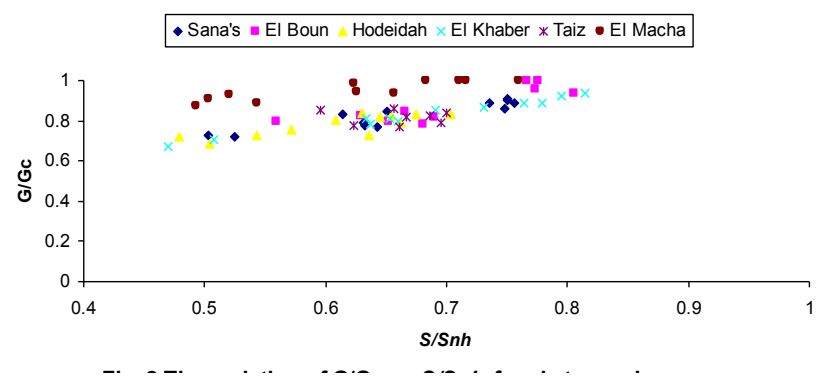

Fig. 2. The variation of $\mathrm{G} / \mathrm{G}_{\mathrm{c}} \mathrm{Vs} S / \mathrm{S}_{\mathrm{nh}}$ for six towns in Yemen.

$\mathrm{G} / \mathrm{G}_{\mathrm{c}}=1.0196\left(S / S_{n h}\right)^{0.4421}$

$\mathrm{G} / \mathrm{G}_{\mathrm{c}}=0.3642 \ln \left(S / S_{n h}\right)+1.0038$

$\mathrm{G} / \mathrm{G}_{\mathrm{c}}=0.5279 \mathrm{e}^{0.7132\left(S / S_{n h}\right)}$

The effect of $S / S_{n h}$ ratio on $\mathrm{G} / \mathrm{G}_{\mathrm{c}}$ for summer (AprilSeptember) is investigated by various regression analyses and the results are given below.

$\mathrm{G} / \mathrm{G}_{\mathrm{c}}=0.3844\left(S / S_{n h}\right)+0.5737$

$\mathrm{G} / \mathrm{G}_{\mathrm{c}}=0.8047\left(S / S_{n h}\right)^{2}-0.562\left(S / S_{n h}\right)+0.8475$

$\mathrm{G} / \mathrm{G}_{\mathrm{c}}=40.917\left(\mathrm{~S} / \mathrm{S}_{n h}\right)^{3}-72.975\left(\mathrm{~S} / \mathrm{S}_{n h}\right)^{2}$ $+43.391\left(S / S_{n h}\right)-7.7962$

$\mathrm{G} / \mathrm{G}_{\mathrm{c}}=0.933\left(S / S_{n h}\right)^{0.2939}$

$\mathrm{G} / \mathrm{G}_{\mathrm{c}}=0.2227 \ln \left(S / S_{n h}\right)+0.9198$

$\mathrm{G} / \mathrm{G}_{\mathrm{c}}=0.5915 \mathrm{e}^{0.5057\left(S / S_{\mathrm{nh}}\right)}$

The results of various regression analyses applied for winter (October - March) are given below.

$\mathrm{G} / \mathrm{G}_{\mathrm{c}}=0.6323\left(S / S_{n h}\right)+0.4375$

$\mathrm{G} / \mathrm{G}_{\mathrm{c}}=3.0574\left(S / S_{n h}\right)^{2}-3.6857\left(S / S_{n h}\right)+1.9508$

$\mathrm{G} / \mathrm{G}_{\mathrm{c}}=-74.908\left(S / S_{n h}\right)^{3}+161.53\left(S / S_{n h}\right)^{2}$ $-114.94\left(S / S_{n h}\right)+27.87$

$\mathrm{G} / \mathrm{G}_{\mathrm{c}}=1.0522\left(S / S_{n h}\right)^{0.5052}$

$\mathrm{G} / \mathrm{G}_{\mathrm{c}}=0.4389 \ln \left(S / S_{n h}\right)+1.0383$

$\mathrm{G} / \mathrm{G}_{\mathrm{c}}=0.5269 \mathrm{e}^{0.7278\left(S / S_{\mathrm{nh}}\right)}$

\section{Comparison Methods}

In this study, two statistical tests, root mean square error (RMSE) and mean bias error (MBE), and t-statistic were used to evaluate the accuracy of the correlations described above. 


\subsection{Root mean square error}

The root mean square error is defined as

$\mathrm{RMSE}=\left(\frac{1}{N} \sum_{i=1}^{N}\left(G_{i, \text { pre }}-G_{i, \text { meas }}\right)^{2}\right)^{1 / 2}$

where $\mathrm{G}_{i, p r e}$ is $i$ th predicted value, $\mathrm{G}_{i, \text { meas }}$ is the $i$ th measured value, and $N$ is the total number of observations. The RMSE is always positive, a zero value is ideal. This test provides information on short- terms performance of the correlation by arranging a term by term comparison of the actual deviation between the calculated value and the measured value. The smaller the value, the better the model's performance. However, a few large errors in the sum can produce a significant increase in RMSE.

\subsection{Mean bias error}

The mean bias error is defined as

$\operatorname{MBE}=\frac{1}{N} \sum_{i=1}^{N}\left(G_{i, \text { pre }}-G_{i, \text { meas }}\right)$

This test provides information on the long term performance. A low MBE is desired. Ideally a zero value of MBE should be obtained. A positive value gives the average amount of over-estimation in the calculated value and vice versa. A drawback of this test is that over estimation of an individual observation will cancel under estimation in a separate observation.

It is obvious that each test by itself may not be an adequate indicator of a model's performance. It is possible to have a large RMSE value and at the same time a small MBE (a large scatter about the line of perfect estimation). On the other hand, it is also possible to have a relatively small RMSE and a relatively large MBE ( a consistently small over - or under - estimation).

However although these statistical indicators generally provide a reasonable procedure to compare models, they do not objectively indicate whether a model's estimates are statistically significant, i.e., not significantly different from their measured counterparts. In this article an additional statistical indicator, the $t$-statistic was used. This statistical indicator allows models to be compared and at the same time indicate whether or not a model's estimates are statistically significant at a particular confidence level [11]. It was seen that the $t$-statistic used in addition to the RMSE and MBE gave more reliable and explanatory results [12].

\subsection{Derivation of the t-statistic from the RMSE and MBE}

The t-statistic is defined as [13],

$t=\frac{\frac{1}{N} \sum_{i=1}^{N} d_{i}}{\frac{S}{N^{1 / 2}}}$

where $N$ is the numbers of data pairs, $d_{i}$ is the difference between $i$ th estimated value and $i$ th measured value and $\mathrm{S}$ is the standard deviation of the difference between estimated and measured values and is given by:

$$
S^{2}=\frac{N \sum_{i=1}^{N} d_{i}-\left(\sum_{i=1}^{N} d_{i}\right)^{2}}{N(N-1)}
$$

Rearranging the equations (25) and (26) gives;

$$
\sum_{i=1}^{N} d_{i}^{2}=N(\mathrm{RMSE})^{2}
$$

$$
\sum_{i=1}^{N} d_{i}=N(\mathrm{MBE})
$$

Combining Eqs. (40) and (43) yields;

$$
t=\frac{M B E}{\frac{S}{N^{1 / 2}}}
$$

Using the equations (42) and (43) in conjunction with Eq. (41) gives:

$S=\left(\frac{N\left(R M S E^{2}-M B E^{2}\right)}{N-1}\right)^{1 / 2}$

Substituting for $\mathrm{S}$ in equation (40) yields:

$t=\left[\frac{(N-1) M B E^{2}}{R M S E^{2}-M B E^{2}}\right]^{1 / 2}$

The smaller the value of $t$, the better is the model's performance. To determine whether a model's estimates are statistically significant, one simply has to determine a critical $t$ value obtainable from standard statistical tables, at a particular confidence level, i.e. $t_{\alpha / 2}$ at the $\alpha$ level of significance and $(N-1)$ degrees of freedom. For the model's estimates to be judged statistically significant at the $1-\alpha$ confidence level, the calculated $t$ value must be less than the critical $t$ value.

\section{Results and Discussion}

If we group the developed equations which include different variables and two period of year, the comparison will be more detailed.

GROUP I [Eqs. (14) - (19)]: the developed equations which include the whole year by using $S / S_{o}$ parameter.

GROUP II [Eqs. (20) - (25)]: equations for both summer and winter by using $S / S_{o}$ parameter.

GROUP III [Eqs. (26) - (31)]: equations which include the whole year by using $S / S_{n h}$ variable.

GROUP IV [Eqs. (32) - (37)]: equations for two period of year, summer and winter by using $S / S_{n h}$ parameter.

It was shown in Table 5 that the good results were not seen in the short term but, relatively good results were seen in the long term. Eq. (17) has the best result among the equation developed in Group I. Similarly the best MBE and RMSE values were obtained by Eq. (22) in Group II. 
Table 5. RMSE and MBE for the equation developed for Yemen.

\begin{tabular}{|c|c|c|}
\hline $\begin{array}{l}\text { Equation } \\
\text { number }\end{array}$ & RMSE & MBE \\
\hline \multicolumn{3}{|l|}{ Group I } \\
\hline 14 & 0.4644 & 0.0115 \\
\hline 15 & 0.4586 & 0.0106 \\
\hline 16 & 0.4579 & 0.0147 \\
\hline 17 & 0.4661 & -0.0053 \\
\hline 18 & 0.4698 & 0.0124 \\
\hline 19 & 0.4612 & -0.0061 \\
\hline \multicolumn{3}{|l|}{ Group II } \\
\hline 20 & 0.4559 & 0.0063 \\
\hline 21 & 0.4535 & 0.0064 \\
\hline 22 & 0.4413 & -0.0011 \\
\hline 23 & 0.4554 & -0.0108 \\
\hline 24 & 0.4570 & 0.0064 \\
\hline 25 & 0.4544 & -0.0101 \\
\hline \multicolumn{3}{|l|}{ Group III } \\
\hline 26 & 0.4644 & 0.0119 \\
\hline 27 & 0.4587 & 0.0108 \\
\hline 28 & 0.4578 & 0.0124 \\
\hline 29 & 0.4661 & -0.0056 \\
\hline 30 & 0.4698 & 0.0127 \\
\hline 31 & 0.4613 & -0.0063 \\
\hline \multicolumn{3}{|l|}{ Group IV } \\
\hline 32 & 0.4559 & 0.0066 \\
\hline 33 & 0.4539 & 0.0065 \\
\hline 34 & 0.4417 & 0.0108 \\
\hline 35 & 0.4554 & -0.0107 \\
\hline 36 & 0.4570 & 0.0065 \\
\hline 37 & 0.4544 & -0.0106 \\
\hline
\end{tabular}

When we compared the developed equation in Group III, the best MBE and RMSE values were seen in Eq. (29) and Eq. (28) respectively, Similarly in Group IV, the best MBE and RMSE values were seen in Eq. (33), (36) and Eq. (34) respectively. When we investigate all the equations the best MBE value was seen in Eq. (22). The best RMSE value were obtained with Eq.(22) and Eq. (34) and these equations are from Group II and Group IV.

Considering the whole country and each city, the performances of developed equations are different. Therefore, the MBE and RMSE values of the developed equations for each city were calculated. The results of the statistical comparison are given in Table 6 .

At the first view, it was seen that the MBE and RMSE values of table 6 are higher than the table 5. Each equation according to the city was compared with the equations in its group. The results obtained were set up in order below.

Sana'a:- Eq (19) in Group I has the best result and in Group II, Eq. (25) has the better result. A relatively good result was obtained by Eq. (31) in Group III. In Group IV the best MBE and RMSE values were obtained by Eq. (33) and (37), and Eq. (35) and (37) respectively.

El Boun:- The best result in Group I and II, were obtained by Eq. (16), and Eq. (21) and (22), respectively. Similarly the best MBE and RMSE values in Group III and IV were obtained by Eq. (28) and Eq. (33) respectively.
Hodeidah:-In group I and II, the best values of MBE and RMSE were obtained by Eq. (19) and Eq. (25) respectively. Similarly Eq. (31) and Eq. (37) give the better result for MBE and RMSE values in Group III and IV respectively.

El Khaber:- Eq. (17) in Group I, Eq. (22) and (23) in Group II, Eq. (29) in Group III, and Eq. (35) in Group IV showed relatively good results.

Taiz:- Eq. (16) in Group I, Eq. (22) in Group II, Eq. (28) in Group III and Eq. (34) in Group IV, showed relatively better results.

El Macha:- Eq. (16) in Group I, Eq. (22) in Group II, Eq. (27) in Group III and Eq. (34) in Group IV, showed the lowest error.

Although the models give good results for the whole country (Table 5), the highest errors were obtained for cities (Table 6). These tables did not include adequate information about performance of the developed equations. In addition to the above mention investigation of results of the $t$-statistic method which is applied to the equation developed, can be useful. The critical $t$-values are shown in Table 7. $t$-values higher than the critical $t$-values show that the equation has no statistical significance.

In Table 7 , having higher $t$-values than the critical $t$ value, a lot of equations are statistically significant because of having lower $t$-values than the critical $t$-value.

Equations of Group I and III has unlogical results, but equations of Group II and IV showed good and logical results in case of Sana'a, El Khaber and El Macha. In case of El Boun equations of Group I and III gave significant results, but equations of Group II and IV could not. In case of Hodeidah Eq. (15), (16), (19), (22), (27), (28), (31) and (34) are significant. Taiz has the least number of significant equations, i.e. only 6 , and these are Eq. (15), (16), (19), (27), (28) and (31).

A summary of the developed equations which gave the better results, according to the whole country and cities can be clearly seen in Table 8. As can be understood from Tables 5, 6, 7 and 8, for the whole country, the equations which include two periods of the year, summer and winter, should be preferred because of having the best results and also for Sana'a, El khaber and El Macha. But for El Boun, Hodeidah and Taiz equations developed for the whole year are preferred because of the better results.

Having approximately the same performance, comparison of $S / S_{o}$ and $S / S_{n h}$ ratios is more difficult.

\section{Conclusions}

In this study, first of all it was seen that the clear sky solar radiation can be used to estimate the global radiation in Yemen.

It was seen that the equations which include the summer and winter periods gave the better results, than the others in all of the developed equation (Table 5). It is a predictable result that the performance of the equations is different for the whole country and for the cities.

Eq. (17), (19) - (22), (24), (29), (31) - (33) and (36) gave the best results among all of the developed equations. It can be said that all the analyses were harmonious.

Finally these results clearly indicate that reliance on the RMSE and MBE used separately can lead to a wrong decision in selecting the best model suited from the candidate models and that the use of the RMSE and MBE in isolation is not an adequate indicator of model performance. Therefore, the $t$-statistic should be used in conjunction with 
Table 6. The RMSE and MBE values of the equation developed for each city.

\begin{tabular}{|c|c|c|c|c|c|c|c|c|c|c|c|c|}
\hline \multirow[b]{2}{*}{ Equation } & \multicolumn{2}{|c|}{ Sana'a } & \multicolumn{2}{|c|}{ EI Boun } & \multicolumn{2}{|c|}{ Hodeidah } & \multicolumn{2}{|c|}{ El Khaber } & \multicolumn{2}{|c|}{ Taiz } & \multicolumn{2}{|c|}{ El Mecha } \\
\hline & RMSE & MBE & RMSE & MBE & RMSE & MBE & RMSE & MBE & RMSE & MBE & RMSE & MBE \\
\hline \multicolumn{13}{|l|}{ Group I } \\
\hline 14 & 0.2695 & 0.1803 & 0.3758 & -0.0160 & 0.3562 & 0.2875 & 0.2704 & 0.2285 & 0.3622 & 0.2361 & 0.8678 & -0.8489 \\
\hline 15 & 0.2659 & 0.1775 & 0.3323 & -0.0109 & 0.3572 & 0.2722 & 0.3152 & 0.2637 & 0.3297 & 0.1867 & 0.8595 & -0.8416 \\
\hline 16 & 0.2719 & 0.1805 & 0.3304 & 0.0002 & 0.3628 & 0.2793 & 0.3075 & 0.2659 & 0.3215 & 0.1857 & 0.8587 & -0.8404 \\
\hline 17 & 0.2614 & 0.1631 & 0.3883 & -0.0369 & 0.3462 & 0.2759 & 0.2511 & 0.2019 & 0.3568 & 0.2295 & 0.8832 & -0.8640 \\
\hline 18 & 0.2770 & 0.1815 & 0.3976 & -0.0208 & 0.3644 & 0.2982 & 0.2635 & 0.2133 & 0.3737 & 0.2541 & 0.8686 & -0.8486 \\
\hline 19 & 0.2548 & 0.1620 & 0.3659 & -0.0312 & 0.3389 & 0.2650 & 0.2593 & 0.2177 & 0.3454 & 0.2108 & 0.8827 & -0.8643 \\
\hline \multicolumn{13}{|l|}{ Group II } \\
\hline 20 & 0.2781 & 0.1762 & 0.3029 & -0.0504 & 0.3643 & 0.2924 & 0.2941 & 0.2118 & 0.3482 & 0.2732 & 0.8553 & -0.8352 \\
\hline 21 & 0.2724 & 0.1549 & 0.3016 & -0.0462 & 0.3680 & 0.2962 & 0.3087 & 0.2406 & 0.3138 & 0.2563 & 0.8562 & -0.8369 \\
\hline 22 & 0.2923 & 0.1816 & 0.2635 & -0.0632 & 0.3772 & 0.2814 & 0.2720 & 0.2043 & 0.2770 & 0.2231 & 0.8401 & -0.8192 \\
\hline 23 & 0.2661 & 0.1612 & 0.3043 & -0.0649 & 0.3475 & 0.2729 & 0.2756 & 0.1904 & 0.3411 & 0.2613 & 0.8730 & -0.8536 \\
\hline 24 & 0.2802 & 0.1802 & 0.3035 & -0.0518 & 0.3661 & 0.2940 & 0.2922 & 0.2037 & 0.3543 & 0.2777 & 0.8551 & -0.8344 \\
\hline 25 & 0.2646 & 0.1577 & 0.3042 & -0.0625 & 0.3464 & 0.2720 & 0.2783 & 0.1999 & 0.3355 & 0.2571 & 0.8725 & -0.8536 \\
\hline \multicolumn{13}{|l|}{ Group III } \\
\hline 26 & 0.2698 & 0.1807 & 0.3760 & -0.0153 & 0.3564 & 0.2877 & 0.2709 & 0.2291 & 0.3625 & 0.2364 & 0.8675 & -0.8487 \\
\hline 27 & 0.2660 & 0.1777 & 0.3326 & -0.0105 & 0.3573 & 0.2722 & 0.3155 & 0.2642 & 0.3298 & 0.1868 & 0.8593 & -0.8415 \\
\hline 28 & 0.2705 & 0.1782 & $\mathbf{0 . 3 3 0 7}$ & -0.0022 & 0.3612 & 0.2771 & 0.3056 & 0.2637 & 0.3201 & 0.1833 & 0.8606 & -0.8424 \\
\hline 29 & 0.2613 & 0.1628 & 0.3885 & -0.0371 & 0.3459 & 0.2755 & 0.2510 & 0.2018 & 0.3566 & 0.2289 & 0.8835 & -0.8643 \\
\hline 30 & 0.2773 & 0.1818 & 0.3979 & -0.0203 & 0.3646 & 0.2983 & 0.2639 & 0.2138 & 0.3739 & 0.2542 & 0.8683 & -0.8484 \\
\hline 31 & 0.2547 & 0.1619 & 0.3662 & -0.0312 & 0.3387 & 0.2647 & 0.2593 & 0.2177 & 0.3453 & 0.2104 & 0.8829 & -0.8646 \\
\hline \multicolumn{13}{|l|}{ Group IV } \\
\hline 32 & 0.2783 & 0.1765 & 0.3194 & -0.0501 & 0.3648 & 0.2926 & 0.2998 & 0.2122 & 0.3359 & 0.2297 & 0.8518 & -0.8260 \\
\hline 33 & 0.2726 & 0.1551 & 0.3152 & -0.0461 & 0.3683 & 0.2963 & 0.3134 & 0.2408 & 0.2917 & 0.2113 & 0.8528 & -0.8285 \\
\hline 34 & 0.3022 & 0.1935 & 0.2657 & -0.0503 & 0.3855 & 0.2915 & 0.2851 & 0.2169 & 0.2715 & 0.2015 & 0.8274 & -0.8026 \\
\hline 35 & 0.2662 & 0.1614 & 0.3224 & -0.0647 & 0.3476 & 0.2729 & 0.2807 & 0.1906 & 0.3302 & 0.2173 & 0.8639 & -0.8439 \\
\hline 36 & 0.2803 & 0.1804 & 0.3214 & -0.0517 & 0.3665 & 0.2941 & 0.2977 & 0.2040 & 0.3435 & 0.2342 & 0.8518 & -0.8252 \\
\hline 37 & 0.2644 & 0.1572 & 0.3207 & -0.0631 & 0.3462 & 0.2714 & 0.2832 & 0.1995 & 0.3225 & 0.2122 & 0.8697 & -0.8446 \\
\hline
\end{tabular}

Table 7. Critical t-values and the results of t-statistic analyses for each city.

\begin{tabular}{|c|c|c|c|c|c|c|}
\hline Equation & Sana'a & EI Boun & Hodeidah & El Khaber & Taiz & El Macha \\
\hline \multicolumn{7}{|l|}{ Group I } \\
\hline 14 & 2.985 & 0.128 & 4.534 & 5.221 & 2.274 & 14.903 \\
\hline 15 & 2.974 & 0.098 & 3.903 & 5.065 & 1.818 & 15.252 \\
\hline 16 & 2.944 & 0.002 & 4.001 & 5.710 & 1.872 & 15.071 \\
\hline 17 & 2.648 & 0.287 & 4.376 & 4.485 & 2.222 & 14.917 \\
\hline 18 & 2.877 & 0.157 & 4.722 & 4.573 & 2.454 & 14.480 \\
\hline 19 & 2.732 & 0.257 & 4.160 & 5.126 & 2.038 & 15.244 \\
\hline \multicolumn{7}{|l|}{ Group II } \\
\hline 20 & 2.716 & 0.479 & 4.453 & 3.315 & 2.480 & 12.531 \\
\hline 21 & 2.292 & 0.445 & 4.496 & 3.973 & 2.781 & 12.989 \\
\hline 22 & 2.619 & 0.716 & 3.676 & 3.634 & 2.677 & 12.944 \\
\hline 23 & 2.525 & 0.616 & 4.201 & 3.067 & 2.310 & 12.668 \\
\hline 24 & 2.785 & 0.490 & 4.459 & 3.114 & 2.469 & 13.285 \\
\hline 25 & 2.462 & 0.597 & 4.199 & 3.306 & 2.313 & 12.899 \\
\hline \multicolumn{7}{|l|}{ Group } \\
\hline 26 & 2.991 & 0.122 & 4.536 & 5.256 & 2.276 & 14.941 \\
\hline 27 & 2.978 & 0.095 & 3.901 & 5.081 & 1.818 & 15.293 \\
\hline 28 & 2.904 & 0.020 & 3.967 & 5.663 & 1.848 & 15.130 \\
\hline 29 & 2.642 & 0.288 & 4.369 & 4.484 & 2.214 & 14.919 \\
\hline 30 & 2.880 & 0.153 & 4.719 & 4.584 & 2.453 & 14.516 \\
\hline 31 & 2.731 & 0.257 & 4.155 & 5.126 & 2.033 & 15.289 \\
\hline \multicolumn{7}{|l|}{ Group } \\
\hline 32 & 2.718 & 0.477 & 4.454 & 3.323 & 2.479 & 12.554 \\
\hline 33 & 2.295 & 0.443 & 4.492 & 3.982 & 2.780 & 12.961 \\
\hline 34 & 2.765 & 0.578 & 3.832 & 3.888 & 2.930 & 12.623 \\
\hline 35 & 2.529 & 0.614 & 4.204 & 3.068 & 2.313 & 14.439 \\
\hline 36 & 2.789 & 0.489 & 4.460 & 3.121 & 2.466 & 12.355 \\
\hline 37 & 2.452 & 0.602 & 4.188 & 3.292 & 2.312 & 12.876 \\
\hline Critical $t$ & 2.712 & 0.342 & 4.182 & 3.694 & 2.144 & 13.375 \\
\hline
\end{tabular}

Table 8. Results of the compilations.

\begin{tabular}{ll}
\hline Location & Equation number \\
\hline The whole country & $17,22,29,33,36$ \\
Sana'a & 21,33 \\
El Boun & 16,28 \\
Hodeidah & 19,31 \\
El Khaber & 23,35 \\
Taiz & 16,28 \\
El Macha & 22,34 \\
\hline
\end{tabular}

these two indicators to better evaluate a model's performance.

\section{Nomenclature}

$\mathrm{G}_{\mathrm{on}}=$ the extraterrestrial radiation, measured on the plane normal to the radiation on the $n_{\text {th }}$ of the year $\left(\mathrm{W} \mathrm{m}^{-2}\right)$

$\mathrm{G}_{\mathrm{sc}}=$ solar constant $\left(1367 \mathrm{~W} \mathrm{~m}^{-2}\right)$

$\mathrm{G}_{\mathrm{cb}}=$ the clear sky beam radiation $\left(\mathrm{W} \mathrm{m}^{-2}\right)$

$\mathrm{G}_{\mathrm{cd}}=$ the clear sky diffuse radiation $\left(\mathrm{W} \mathrm{m}^{-2}\right)$

$H=$ monthly mean daily global radiation on a horizontal surface $\left(\mathrm{MJ} \mathrm{m}^{-2}\right)$

$H_{c}=$ clear sky monthly mean daily global radiation on a horizontal surface $\left(\mathrm{MJ} \mathrm{m}^{-2}\right)$

$H o=$ monthly mean daily extraterrestrial radiation $\left(\mathrm{MJ} \mathrm{m}^{-2}\right)$

$\mathrm{Gc}=$ the clear sky global solar radiation $\left(\mathrm{W} \mathrm{m}^{-2}\right)$

$S=$ monthly average daily hours of bright sunshine

$S_{\mathrm{o}}=$ monthly average of maximum possible daily hours of bright sunshine (i.e. day length of average day of the month) $S_{n h}=$ monthly mean sunshine duration taking into account the natural horizon of site 
$a, b=$ empirical constants

$a^{\prime}, b^{\prime}=$ empirical constants

A $=$ altitude $(\mathrm{km})$

Greek symbols

$\theta_{\mathrm{z}}=$ zenith angle (degree)

$\tau_{\mathrm{b}}=$ atmospheric transmittance for beam radiation

$\tau_{\mathrm{d}}=$ atmospheric transmittance for diffuse radiation $\omega=$ the sunset hour angle, the angular displacement of the sun east or west of the local meridian due to the rotation of the earth on its axis at $15^{\circ}$ per hour (morning negative afternoon positive), in degrees

$\phi \quad=$ latitude, the angular location north or south of the equator, north positive

$\delta=$ declination angle

\section{References}

1. Munroe MM. Estimation of totals of irradiance on a horizontal surface from UK average meteorological data. Solar Energy 1980; 24: 235

2. Khogali A, Ramadan MRI, Ali ZEH, Fattah YA. Global and diffuse solar irradiation in Yemen (Y.A.R). Solar Energy 1983;31:55

3. Leung CT. The fluctuation of solar irradiation in Hong Kong. Solar Energy 1980;25:485.

4. Ezekwe GI, Ezeilo CCO. Measured solar radiation in a Nigerian environment compared with predicted data. Solar Energy 1981;26:181.

5. Khogali A, Solar radiation over Sudan--- comparison measured and predicted data. Solar Energy 1983;31:45.

6. Angstrom A. Solar and atmospheric radiation. Qr J R Meteor Soc 1924;50:121.

7. Page JK. The estimation of monthly mean values of daily total short wave radiation on vertical and inclined surfaces from sunshine records for latitudes 40 N-- 40 S. Proc of UN Conf on New Sources of Energy 1964;4:378.

8. Togrul IT. Estimation of clear sky radiation in Elazig, Chimica Acta Turcici (in press) 1999;27(1).
9. Hottel HC. A simple model for estimating the transmittance of direct solar radiation through clear atmosphere. Solar Energy 1976;18:129.

10. Liu BYH, Jordan RC. The interrelationship and characteristis distribution of direct, diffuse and total solar radiation. Solar Energy 1960;4(3): 1 .

11. Stone RJ. Improved statistical procedure for the evaluation of solar radiation estimation models. Solar Energy 1993;51:289.

12. Togrul IT. Comparison of statistical performance of seven sunshine based models for Elazig, Turkey, Chimica Acta Turcica 1998;26:37.

13. Walpole RE, Mayers RH. Probability and statistics for engineers and scientists. 4th ed. New York: Macmillan, 1989.

14. Sahin AD. A new formulation for solar radiation and sunshine duration estimation. International Journal of Energy Research 2007; 31(2):109-118.

15. Ahmad MJ, Tiwari GN. Evaluation and comparison of hourly solar radiation models. International Journal of Energy Research 2009; 33: 538-552. 